\title{
Fam. Aulacomniaceae.
}

\section{Aulacomnium.}

144. A. androgynum. Krěer Wald bei Prag, auf festem Waldboden am Grunde der Bäume, auch an erdbedeckten Wurzeln, steril! - In der vorderen Scharka, steril (lgt. Velenovský)! In Felslöchern in der Wilden Scharka, steril!

145. A. palustre. Feuchte Waldstellen bei Ridotin, steril eum pseudopodiis! - Sumpfige Wiesen bei Hodkowička nächst Prag, c. fr. et Var. polycephalum, steril!

(Fortsetzung folgt.)

\section{Zwei neue Moose der böhmischen Flora.}

Von Univ.-Assistent Franz Matouschek. (Prag.)

\section{Philonotis calcarea (Bryol. europ.) Schimp. Var. fluitans Matouschek.}

Pflanze bis $13 \mathrm{~cm}$ lang, fluthend an Steinen in Bächen, sehr feinstengelig, einfach oder auch mit gabelig abzweigenden Aesten, häufig mit blattwinkelständigen Kurztrieben, schmutziggrün. Blätter nicht einseitswendig, lockerstehend, im trockenen Zustande verkrümmt abstehend, mit zum Stamme einwärts gebogenen Spitzen, feucht aber aufrecht abstehend; an den Spitzen des Stammes und der Aeste im fenchten und trockenen Zustande knospenförmig zusammenschliessend. Stengelfilz äusserst spärlich, hellbrüunlich. Stengelquerschnitt dreieckig-oval. Grundgewebe locker, weitzellig, mit länglichem, ziemlich eng- und reichzelligem Centralstrange. Alle Zellen, auch die des Centralstranges röthlichbraun gefärbt. Der Strang leuchtet an den Spitzen der Stämme als rothes Band durch die Rinde und Blätter hindurch.

\& Blüten unbekannt. $\sigma$ Blüten dick, scheibenförmig, von denen der Stammform dadurch verschieden, dass nur die innersten Hüllblätter eine auslaufende Rippe besitzen. Im Uebrigen sind die Hüllblätter von den Stammblättern der $\sigma^{*}$ Pflanze nicht verschieden. Diese letzteren sind aus breitovalem Grunde lanzettförmig, allmählich zugespitzt, vollkommen flachrandig, nicht gefurcht, oberhalb der ungezähnten Basis gegen die Spitze zu immer schärfer gezähnt. Rippe kräftig, sich allmählich verschmälernd und in der Spitze verschwindend, also nicht austretend. - Die Blätter der sterilen Pflanzen sind etwas schmäler und hie und da oberhalb des Blattgrundes sehr schmal umgerollt. Blattgrund und Blattspitze sind stets flach. Blattinsertion meist etwas röthlich. Die untersten Stamm- 
blätter sind bis auf die kräftige Rippe macerirt. Die Blattzellen sind nicht getüpfelt, in den oberen und unteren Zellecken mamillös-papillös, oval-rectangulär; im oberen Blatttheile anderthalb bis zweimal so lang als breit, gegen den Grund breiter, jedoch im Verhältnisse zu ihrer Breite nicht viel mehr wie zweimal so lang als breit. - Auffallend dureh ihre Blätter sind die knospenförmigen Kurztriebe, indem ihre unteren Blätter sehr klein, breiteiförmig, fast ebenso lang als breit, abgerundet und kurz zugespitzt sind und ein ganz lockeres, hyalines Zellgewebe haben. Die untersten von diesen Blättern sind ganz rippenlos, die weiteren mit sehr dünner, flacher, weit unter der Spitze endigender Rippe, die nächst obcren mit dicht vor der Spitze endigender ebenso dünner Rippe versehen. Die oberen Blätter nehmen allmählich eine kurzzugespitzte, spatelförmige Form und schliesslich die Gestalt der Stengelblätter an, sind jedoch bedeutend kürzer und schmäler. Alle Knospenblätter sind vollständig flach, ungefaltet. Die erwähnten eifürmigen Knospenblätter sind vollständig ungezähnt, die spatelförmigen nur an der Spitze äusserst feine Zähne zeigend, die übrigen normal. - Die Pflanze unterscheidet sich durch die angegebenen Merkmale von der in Limpricht: die Laubmoose ete. II. pag. 564 i. ff. gegebenen Beschreibung der Stammform deutlich und steht nach der ebenda angeführten Diagnose der Varietas $\beta$ mollis Venturi nahe, unterscheidet sich aber auch von dieser durch die merkwürdigen Kurztriebe und deren Beblätterung, durch die nicht anslaufenden Rippen und das Zellnetz. wobei vorausgesetzt wird, dass die genannte Varietät in diesen Punkten mit der Stammdiagnose übereinstimmt, weil Limpricht in diesen Beziehungen Unterschiede nicht hervorgehoben hat. Ueberdies ist der Standort meiner Varietät von der genannten Venturi'schen Pflanze sehr verschieden, indem Var. fluitans fluthend in Gebirgsbächen, Var. mollis an feuchten Stellen eines Weges bei Meano im Trentino entdeckt wurde.

Der Beschreibung der Var. fluitans liegt zu Grunde das von mir Anfangs October 1895 im Jeschkengebirge gesammelte sterile Material und ein Rasen G-Pflanzen, welcher von F. Arnold in Weissenburg in Franken (Baiern) gesammelt und sonderbarer Weise trotz des auffallend abweichenden Habitus mit anderen typischen Rasen der Stammpflanze auf denselben Carton aufgeklebt mit der Scheda: Philonotis calcarea ausgegeben wurde.

Die Pflanze von Weissenburg unterscheidet sich von der aus dem Jeschkengebirge stammenden durch den fast vollständigen Mangel der Kurztriebe, ferner dadurch, dass die Blattränder an dieser Pflanze stets vollständig flach sind und das Blattnetz etwas schmälere und längere Zellen aufweist, ausserdem dadurch, dass die Blattspitzen der Stengelblätter nicht so regelmässig dem Stamme zugekrümmt sind wie bei der sterilen Pflanze, sondern häufig auch flattrig abstehen. 
Herr J. Breidler war so gütig, die böhmische Pflanze zu untersuchen und deren Zugehörigkeit zur Phil. calcarea zu bestätigen. Standorte:

1. Jesckkengebirge in Böhmen: Im Bache unterhalb des "Böhmischen Franz" am Jeschkengebirgskamme, etwa 1/4 Stunde von Swétla entfernt and etwa 100 Schritte von mergeligen mittelturonen Kreideablagerungen gelegen, fluthend auf Quarzitblöcken, in Gesellschaft von häufigem Hypnum virescens Boulay, $700 \mathrm{~m}$ Seehöhe. Bisher nur steril gefunden.

2. Weissenburg in Franken, legit F. Arnold, in Herb. Dr. J. B. Holzinger (jetzt in meinem Herbar.).

Unsere vielen europäischen Philonotis-Formen sind bis jetzt in keinem Werke erschöpfend bearbeitet. Eine gründliche Revision der Gattung vorzunehmen, wäre sicher an der Zeit. Da ich nun dem Formenkreise der Gattung Philonotis gern näher treten möchte, ersuche ich die Herren Bryologen, denen diese Arbeit in die Hände kommt, um die gütige Mittheilung möglichst vieler Formen aus dieser Gruppe mit genauen Standortsangaben.

2. Polytrichum ohioense Ren et Cardot in Rev. bryol. 1885 pag. 11 u. 12.

Riesengebirge: Am "Weberwege" im Weisswassergrunde (circa $820-950 \mathrm{mi}$ ) bei Spindelmühle, an mehreren Stellen, gesammelt im August 1896 von Herrn E. Ha usen, Militärapotheker, derzeit in Potsdam. Genannter Herr ist der Entdecker dieser seltenen Polytrichum-Art für Böhmen. - Im preussischen Antheile des Riesengebirges ist diese Pflanze neuerdings an einigen Orten von Herrn K. G. Limpricht nachgewiesen worden, z. B. an Felsblöcken im Walde zwischen Josephinenhütte und der Gebertsbaude $(800 \mathrm{~m})$, nahe der österreichischen Grenze, am 30. Juli 1896, c. fr. Auch in den preussischen Ausläufern des Isergebirges fand es Limpricht, so am Ziegenstein in der Nähe des Hochsteines. Es steht zu erwarten, dass diese Art auch auf dem Isergebirgskamme und wohl auch auf dem böhmischen Abfalle des Riesengebirges zu finden sein wird. (Herrn Oberlehrer Limpricht bin ich für diese Angaben zu bestem Danke verpflichtet.) - In Oesterreich ist dieses Moos meines Wissens bisher nur im Suldenthal am Ortler u. zw. 1887 von Dr. Julius Röll gæefunden worden. Ueber die sonstige Verbreitung siehe Röll: Beiträge zur Moosflora von Nordamerika (Hedwigia" 1897, 36. Bd., pag. 45) und die hier citirte Literatur.

\section{Zur Flora von Vorarlberg und Liechtenstein.}

Von Prof. Gottfr. Richen S. I. (Feldkirch).

(Fortsetzung.)

Geraniaceae.

Geranium sanguineum L. Canisfluh (A, R). Hoher Frassen (W). G. molle L. Hier und da um Feldkirch (A), z. B. am Wege nach Amberg, am Veitskapf. Tisis (R). 